\title{
The European military helicopter industry: Trends and perspectives
}

\section{Josselin Droff}

Josselin Droff is Researcher at the Chair of Defense Economics at the Endowment Fund of the Institute for Higher National Defense Studies (Fonds de Dotation de l'Institut des Hautes Etudes de Défense Nationale, IHEDN), Paris, France. He may be reached at Josselin.Droff@fdd-ihedn.fr.

\section{Abstract}

This article discusses the European military helicopter market. It first recalls historical antecedents in the structural development of the main helicopter programs that helped to consolidate the industry and then reviews the industry's current major trends. A paradoxical situation is identified: While European countries presently are able to cope with both, the growing needs in helicopter capabilities and the maintenance of ageing fleets, no large helicopter programs for the future have been launched. Some uncertainties regarding how future helicopter procurement will be organized are identified. The current situation underlines the challenges that European states will face to maintain both industrial skills in the industry and sovereignty in military helicopter capabilities. A number of industry options are discussed: more exports, more cooperation, more dual use, and more reliance on support and service sales.

$\mathrm{M}$ ilitary helicopters have become a major defense system, and states use them extensively in military operations. Helicopters - for combat, transport, or multirole uses - provide modularity and flexibility to project forces at home and abroad. Due to certain operating characteristics, e.g., the ability to take off and land vertically, hover for extended periods of time, and aircraft handling properties at low-speed, these weapons platforms are used to conduct missions that are not possible with other aircraft. Military needs for the use of helicopters are diverse. They now are used in escort missions, support missions, and ground force protection in conjunction with fixed-wing aircraft. Since the 1950s, military helicopters have become a key element of air mobility, based on the dual-named "terrestrial/rotary-wing" concept, the combination of being able to transport ground units carrying out operations while supporting them with scouting, transport, or combat capabilities. Depending on the type of mission (payload, distance to cover, and so on), helicopters have progressively become an alternative to manned fixed-wing aircraft. ${ }^{1}$

European countries involved in military operations use helicopters extensively. For example, French armed forces recently asked for a significant reinforcement with helicopters forces for the Barkhane operation in the Sahel sub-Saharan region. This involved a mix of Tiger (5 years old in 2016) and Gazelle (30 years old) combat helicopters as well as Puma (41 years old) and Cougar ( 25 years old) transport helicopters.

On the demand side, the need for aero mobility has increased. Military helicopters are among Europe's procurement priorities. This is especially true for transport helicopters, with 14 countries engaged in a purchasing or upgrading process since 2011. However, many uncertainties exist that affect this market's evolution. For instance, defense budgets are constrained and military helicopters require large investments in terms of acquisition and ongoing support. This requires constant examination of this industry in Europe. ${ }^{2}$

On the supply side, competition is fierce. The estimated world-wide market is about 1,000 platforms annually, with the American market representing roughly 66 percent of the total. In 2016, the market was shared among three American, two European (Airbus Helicopters and Leonardo Helicopters), and one Russian (Russian Helicopters, part of Oboronprom) manufacturers. In addition, two Japanese, one Indian, and one Chinese firm produce licensed platforms developed by the American, European, and Russian firms. ${ }^{3}$

In what follows, the two main sections of this article discuss, first, the history and current situation of consolidation in the European military helicopter industry and, second, options for its future. A final section concludes.

\section{History and current situation}

Prior to world war two, helicopter development took place in European countries such as France, Germany, Italy, Spain, and the United Kingdom. While the German Focke-Wulf FW-61 was the first operational helicopter to fly, in 1936, European production numbers were low. The first helicopter to reach industrial scale production was the American Sikorsky R-4, with a production order for around 100 aircraft in 1942, and it was the only Allied helicopter to serve in world war two. After the war, the transfer of U.S. helicopter technology through 
Table 1: Military helicopter market (2015): Major actors and home countries in the European market

\begin{tabular}{|c|c|c|c|c|c|}
\hline Manufacturer & $\begin{array}{l}\text { Military/ } \\
\text { total sales } \\
\quad(\%)\end{array}$ & $\begin{array}{l}\text { Number of } \\
\text { employees }\end{array}$ & $\begin{array}{l}\text { Turnover } \\
\text { (USD } \\
\text { billions) }\end{array}$ & $\begin{array}{l}\text { Number of } \\
\text { platforms in } \\
\text { Europe }^{a}\end{array}$ & $\begin{array}{c}\text { Share of } \\
\text { European } \\
\text { platforms }(\%)\end{array}$ \\
\hline $\begin{array}{l}\text { Europe } \\
\text { - Airbus Helicopters (French, German, Spanish) } \\
\text { - Leonardo Helicopters (Italy) }\end{array}$ & $\begin{array}{l}48 \\
42\end{array}$ & $\begin{array}{l}22,900 \\
13,000\end{array}$ & $\begin{array}{l}8.3 \\
5.6\end{array}$ & $\begin{array}{c}1,366 \\
383\end{array}$ & $\begin{array}{l}38 \\
11\end{array}$ \\
\hline $\begin{array}{l}\text { United States } \\
\text { - Sikorsky Helicopters } \\
\text { - Bell Helicopters } \\
\text { - Boeing Defense, Space, and Security }\end{array}$ & $\begin{array}{c}79 \\
62 \\
100\end{array}$ & $\begin{array}{l}15,300 \\
8,700 \\
\mathrm{n} / \mathrm{a}\end{array}$ & $\begin{array}{c}7.5 \\
4.2 \\
3.2^{b}\end{array}$ & $\begin{array}{l}294 \\
750 \\
319\end{array}$ & $\begin{array}{c}8 \\
21 \\
9\end{array}$ \\
\hline Russia: Russian Helicopters & 90 & 42,000 & 3.5 & 371 & 10 \\
\hline $\begin{array}{l}\text { Japan } \\
\text { - Mitsubishi Heavy Industries } \\
\text { - Kawasaki Heavy Industries }\end{array}$ & $\begin{array}{l}12^{\mathrm{c}} \\
\mathrm{n} / \mathrm{a}\end{array}$ & $\begin{array}{l}\mathrm{n} / \mathrm{a} \\
\mathrm{n} / \mathrm{a}\end{array}$ & $\begin{array}{l}\mathrm{n} / \mathrm{a} \\
\mathrm{n} / \mathrm{a}\end{array}$ & $\begin{array}{l}0 \\
8\end{array}$ & $\begin{array}{c}0 \\
0.2\end{array}$ \\
\hline India: Hindustan Aeronautics Ltd. & $95^{c}$ & $\mathrm{n} / \mathrm{a}$ & $\mathrm{n} / \mathrm{a}$ & 0 & 0 \\
\hline China: Changhe Aircraft Industries Corporation & $\mathrm{n} / \mathrm{a}$ & 4,300 & $\mathrm{n} / \mathrm{a}$ & 0 & 0 \\
\hline
\end{tabular}

Sources: Compiled from James (2016), Meddah (2016), SIPRI (2016), and manufacturers' data. Notes: ${ }^{\text {a }}$ The number of platforms is for 2016 (IISS, 2016). ${ }^{\mathrm{b}}$ The figure is the turnover Boeing Defense, Space, and Security only. ${ }^{\mathrm{c}}$ The figure is for the entire company. n/a: Not available.

licensing agreements led to the emergence of four major European manufacturers: Westland (U.K.), Aerospatiale (France), Messerschmitt-Boelkow-Blohm MBB (Germany), and Agusta (Italy). Today only two European manufacturers remain, Airbus Helicopters and Leonardo Helicopters. Table 1 lists them in the context of the world's major manufacturers and shows various market and business indicators. In 2015, the two European firms shared half of the market in Europe, the three American manufacturers had 38 percent, and the Russian one had 10 percent. Airbus Helicopters produced 38 percent of all platforms in service in 2016 and Leonardo Helicopters 11 percent. $^{4}$

French-British bilateral initiatives: The take-off of industrial integration

In 1915, the English town of Yeovil was known both for its gloving industry (glove production) and for its Petters diesel engine company. Petters placed its facilities and workforce at the government's disposal for the war effort. When it was suggested that the local sewing skills in the gloving industry, combined with Petters engineering, could be adapted to aircraft production, Westland was born. Following the war, the new firm designed a number of civil aircraft and, during the second world war, produced military aircraft (e.g., Lysander, Spitfire, Welkin). Between 1915 and 1955, a total of about 6,000 fixed- wing aircraft were built at Yeovil. ${ }^{5}$

In 1946 Westland negotiated a long-term agreement to build Sikorsky helicopters under license and made the strategic decision to specialize in the production of rotary-wing platforms. In the Royal Navy helicopters rapidly superseded fixed-wing aircraft in anti-submarine warfare and search and rescue operations. In 1960, twenty British aircraft manufacturers combined to form only two major aircraft manufacturing groups, the British Aircraft Corporation and the Hawker Siddeley Group. For rotary-wing platforms, Westland took the lead and successively acquired Bristol Helicopters, Fairey Aviation, and Saunders-Roe to to become Westland Helicopters, Britain's sole helicopter company. The partnership with Sikorsky continued with the production of the Sea King line of models.

Cautious French-British cooperation in the production of military helicopters started with an agreement struck in 1965. The needs were for tactical and transport helicopters and for a light observation and multirole helicopter (including for antisubmarine warfare and antitank missions). This gave birth to the Puma, Gazelle, and Lynx programs and was, for Westland, an important step in its development to become a major European helicopter company. Westland took on the design leadership for the Lynx, while the French partner, Aerospatiale, was responsible for Puma and Gazelle. Both companies, 
however, were to take part in the development and manufacture of all platforms. The three helicopter types have been extensively used by both countries in domestic and foreign operations - many of them are still in service - and were great export successes as well. (For example, more than 1,750 Gazelles were produced, and in past or current use by 27 countries.) Today, however, ageing and obsolescence raises maintenance cost and limits interoperability with other nations' military assets. ${ }^{6}$

\section{Italian-British initiative: The birth of AgustaWestland}

In the mid-1970s, Westland decided to design a larger aircraft, the Westland 30, as a private venture for the civilian market. In part because of the limited success of these aircraft, the mid1980s proved a difficult time for Westland and the firm considered a major link-up with Sikorsky, although European option was preferred. A partnership with Aerospatiale was envisioned but abandoned. In the end, Westland agreed with Agusta of Italy to collaborate on the production of a new helicopter-the AW-101 Merlin-which was to replace the Sea King. In 1986, Sikorsky acquired Westland. Then, in 1994, Westland became a wholly owned subsidiary of GKN, a British multinational automotive and aerospace company. Westland was merged with then-Finmeccanica's Agusta helicopter division in 2001. Finally, in 2004, Finmeccanica S.p.A. acquired GKN's share in the joint venture. As from 2016, the company is called Leonardo Helicopters.

The AW-101 Merlin program was launched by the United Kingdom to respond to national requirements for a modern naval utility helicopter. In 1974 already, the Royal Air Force and the Royal Navy had wanted to replace Westland's Sea Kings. Westland first proposed its own platform, derived from a civilian helicopter, but it was not selected. Meanwhile, in Italy, Agusta had joined a program in 1980 to replace the Agusta-Sikorsky AS-61 which was in service in Italy. Agusta and Westland then formed a joint venture, called Elicoterri Helicopter Industries (EHI), which gave birth to the AW-101 Merlin and subsequently played an important role in the integration of Agusta and Westland. The AW-101 entered into service in 1999. This medium-lift transport helicopter was initially developed for both military and civilian markets. A version was also developed for anti-submarine warfare. The platform has been deployed in combat in Afghanistan and Iraq. In 2016, 98 platforms were in service in 4 European countries (Denmark, Italy, Portugal, and the U.K.

French-German cooperation: The EC-665 Tiger program and the birth of Eurocopter (Airbus Helicopters)

To replace ageing Bo-105, Gazelle, and Puma helicopters,
Helicopters are part of today's strategic defense equipment. In the absence of any large, multi-nation, cooperative program to develop new military helicopters platforms in Europe, a major risk lies in the potential loss of defense industrial and technological knowledge, skills, and military capabilities. This article discusses the potential roles that export expansion, increased cooperation, dual-use production, or a focus on support and services may have in keeping European military helicopter firms "in play."

France and Germany started in 1974 to cooperate to produce a combat helicopter with anti-tank and night vision capabilities. Sud Aviation (later merged in Aerospatiale) and MBB had already worked together in the 1960s on a new rotor and composite blades, but not on a whole system. Moreover, following cooperation failures on European fighter aircraft and battle tanks, by the early 1980s the Tiger program appeared to be the only opportunity to cooperate with Germany. The Tiger program was exemplary in that all procurement segments were shared between countries. It also gave birth to joint training schools, both for pilots - training is particularly expensive in aeronautics-and maintenance personnel. In 2016, 97 platforms were in service in three European countries (France, Germany, and Spain) and in Australia (22 platforms).

In 1992 DASA (Germany) and Aerospatiale (France) merged their helicopter divisions into a new company, Eurocopter. In 2000, both groups agreed to merge and this consolidation included CASA (Spain), with its helicopter business (mainly producing Bo-105s under license) being integrated into Eurocopter. Eventually EADS rebranded itself and all its divisions, and Eurocopter change its name to Airbus Helicopters in 2014. By 2016 Airbus Helicopters had four main facilities in Europe (two each in France and Germany), plus 32 subsidiaries and other operations around the world.

The AW-101 Merlin and Tiger programs played a major role in the integration of Europe's military helicopter industry. AgustaWestland and Eurocopter emerged due to convergence between operational needs for different armed forces and a desire for industrial rationalization. The cooperative programs were an opportunity for firms to build concrete foundations to work together, share skills, knowledge, and infrastructure. This gave birth to what today are two leading European military helicopter companies, Leonardo Helicopters and Airbus Helicopters.

\section{European multilateral programs}

In addition to the (mostly) bi-lateral programs already described, recent multilateral programs such as NH-90 illustrate the limits of European industry consolidation. 
Contrary to programs such as the AW-101 Merlin or Tiger, the NH-90 program had limited effects on integration.

Joint efforts on the NH-90 platform began in late 1970s. As suggested by its name-NATO Helicopter 90-NATO needs influenced this program, which was a response to the main requirements of the so-called Ditchley Park agreements: building a medium transport and multirole helicopter, also capable of operations in naval environments. The NH-90 was developed and manufactured by $\mathrm{NH}$ Industries, an industrial cooperation of Airbus Helicopters, Leonardo, and Fokker Aerostructures. ${ }^{7}$ The program involves several countries. On the supply side, R\&D and production costs were shared among four countries: France, Germany, and Italy carried around 30 percent each and the Netherlands 6 percent. Belgium and Portugal contributed to production costs only, at about 1.5 percent each. Given the total cost, it is likely that the countries would not have been able to afford a platform with such strong technological innovation. On the demand side, as of 2016 a total of thirteen states have placed more than 500 orders for the NH-90. Two versions — one marine, one terrestrial — have been developed.

While impressive, the program has its limits. First, in early service, the NH-90 suffered from technical set-backs, which in turn delayed active deployment by some operators. Second, because of lack of rationalization in terms of the needs of national armies, the NH-90 today is in service in 23 versions, which limits rationalization of maintenance. Third, in the production process itself, little industrial rationalization is noted. Because of the application of juste retour, assembly lines are spread across several countries. Fourth, no merger between industrial actors in the European helicopter industry have taken place during, or after, the scheduling of this program. Contrary to the experiences of the AW-101 Merlin and Tiger programs, for instance, the NH-90 program did not have an effect on Europe-wide military helicopter industry consolidation.

\section{Lack of new European military helicopters programs}

Europe's military helicopter fleets are ageing. A proxy for aging is the date of entry into service. Thus, by 2016, the oldest helicopters are the Bell-204 and Bell-205 Iroquois (first flight in 1956; entry in service in 1959), with a total of 367 platforms in service. The youngest fleet is the AW-159 (first flight in 2009; entry in service in 2015), with a total of 49 platforms in service. Around two-thirds of Europe's military helicopter platforms are based on designs that are more than 35 years old. More precisely, of a total of 3,586 platforms the oldest helicopters (defined here as pre-1980 entry into service) represent 65 percent of the number of helicopters in service in
2016. Another 11 percent came into service between 1980 and 1990, 14 percent between 1990 and 2000, and the remaining 10 percent since then. This age profile and the increasing demand for helicopter capabilities have led to discussions regarding new helicopter programs and replacement solutions.

In Europe, no new common, large programs, such as Tiger or NH-90, are currently planned. In the United States, the Joint Multi-Role Program Helicopter (a multirole platform with vertical take-off, highspeed, and tiltrotor) groups major American manufacturers-Bell, Sikorsky, and Boeing-to develop a demonstrator, which is supposed to fly in 2017. The U.S. also launched a large program of about USD100 billion to replace several ageing platforms including the Chinook, Black Hawk, and Apache. This prompted the acquisition of Sikorsky by Lockheed Martin in 2015 because the latter firm wanted to penetrate the helicopter market. (A demonstrator was built.) In Europe, to avoid dependency on American systems, it would be of interest to take a similar approach to the development of new capabilities and base them on Airbus Helicopters and Leonardo Helicopters, and possibly other countries with which two majors have developed industrial cooperation such as Poland, Spain, or even Turkey.

However, Europe appears to be focused on national initiatives, where several helicopter replacement programs have recently been launched. In 2013, in France, the Ministry of Defense has set up a Joint Light Helicopter program (Hélicoptère Interarmées Léger, HIL). This program aims to develop a family of helicopters based on a dual-use platform. Several versions with different specifications would be put into service in the different services of the armed forces and other government departments (e.g., police and customs). Because of budget cuts and changes in budget planning, the program has been delayed. The platform is not expected to be in operation before 2020-2022. In Italy, in late 2016, Parliament's defense committee approved a funding envelope of EUR487 million to design and develop the successor to the 1980s flagship of AgustaWestland's production, the AW-129 Mangusta attack helicopter (first flight in 1983; 43 platforms in service in Italy in 2016). The design phase of the new platform will involve universities and research centers and the prototype will be built at Leonardo Helicopters's Vergiate factory. The new helicopter will replace the army's AW-129 Mangusta in 2020. The platform has be announced as "all-Italian," but this seems unlikely as Italy does not have an appropriate engine producer in Italy and missiles will have to be sourced from foreign suppliers since the only ones produced in Italy are under foreign license and thus subject to re-export controls.

In short, Europe faces a paradoxical situation: Helicopters are among the most extensively used pieces of equipment in 
military operations today but there exists a lack of large, new programs to address future needs and capabilities. The support of states with large equipment programs (upgrading, retrofitting, or developing new platforms) is crucial. In spite of a history of major military helicopter programs, nothing comparable to current U.S. efforts is found in Europe. The situation is nationally based and only national programs are launched in the light helicopters segment such as multirole and multi-mission platforms to replace ageing light platforms. There is a substantial risk of losing industrial skills and knowledge dearly acquired by European firms and countries between the late 1960s and the mid-1990s.

The future of Europe's helicopter defense industrial base The following subsection review four options that European military helicopter firms and countries may consider.

Exports: Is the future outside Europe?

In the current context (declining defense budgets make purely domestic programs unaffordable; no new large expected multicountry, cooperative programs), cooperative ventures aimed at exports could enlarge the market, maintain industrial skills, and also further industrial integration. But market competition is intense, involves many uncertainties and, depending on the type of export or cooperation, one can also see risks for some strategic skills to leave Europe.

First, European manufacturers can search for export markets in Europe, outside their own domestic market. East European countries are potential candidates, for exports and for joint work. They have growing defense budgets and growing needs in helicopter capabilities (they perceive threats from Russia). For example, Poland needs to replace its ageing Russian platforms, which constitute more than 60 percent of the total number of platforms in service in the country in 2016. The Polish market for 70 multi-mission helicopters is valued at EUR2 billion. Airbus recently lost the Polish market for its EC-725 Caracal when Poland selected 21 Sikorsky S-70 Black Hawk helicopters. Poland also launched a tender for 30 attack helicopters. The choice will be between the Airbus Tiger, Boeing AH-64, and Leonardo Helicopter's AW-129. Another call for tenders has been launched for around 20 special forces helicopters with an offset requirement concerning in-country maintenance of selected platforms. Again, Sikorsky, Airbus Helicopters, and Leonardo Helicopters are in the competition. Many uncertainties cloud these tenders and last minute changes of terms complicate the picture but the strong suggestion is that a European procurement preference should not be presumed to hold for some countries such as Poland for example. This is unlike the case of northern European countries (e.g., Finland,
Netherlands, Norway) that clearly have selected the NH-90 helicopter to modernize their fleets.

\section{Cooperation}

A second option is to intensify the current degree of integration and gain access to new markets while preserving skills and knowledge. But what are the prospects? A merger between Airbus Helicopters and Leonardo Helicopters is unlikely since this would lead to the creation of a civilian helicopter monopoly in Europe. Programs with Russia (e.g., in the heavy transport helicopter segment or even for attack helicopters) or China (an attractive but embargoed market) also are unlikely in the current context. A transatlantic venture is difficult to realize as the prospects for European platforms in the U.S. market are more limited for military than for civilian platforms. The former Aerospatiale did sell some civilian platforms in the U.S. and today, in its legal form of American Eurocopter (the subsidiary of Airbus Group in North America), the manufacturer continues to deliver the UH-72A Lakota (a militarized version of the EC-145, produced in Mississippi) to the U.S. Army. However this is an exception as the Pentagon's market has been hard for European manufacturers to break into (in competition with Bell Helicopters). One should not expect that the military platforms of Airbus Helicopters (e.g., Tiger or NH-90) will make it in the U.S. market. ${ }^{8}$

Regarding Leonardo Helicopters, the VH-71 Kestrel (an adapted version of the AW-101), was developed in cooperation between Lockheed Martin and AgustaWestland to serve in the U.S. presidential transport fleet. The European firm was chosen because, at the time, the American one did not have industrial skills in the design of military helicopters and was more of an electronics specialist dealing with onboard systems and systems integration. However, the program was cancelled due to its expense (more than four billion dollars for nine platforms). This could have been the first step toward a merger between Leonardo and Lockheed Martin, but it failed. Leonardo is also a partner of Bell Helicopters (i.e., Boeing) to develop the AW-609 with a tiltrotor taken from the BoeingBell V-22 military helicopter (expected on the market in 2018).

A transatlantic company is unlikely to emerge. Recall that in 2015 Sikorsky was acquired by Lockheed Martin. It is conceivable that AgustaWestland or Airbus Helicopters might have done the acquisition, but neither did. Instead, Lockheed Martin burst into the helicopter sector, even without industrial consolidation at the U.S. national level. If one looks beyond an American option, new partnerships in emerging or developing countries need to be examined. Airbus Helicopters currently exports to (and produces in) Asia. China is a major market for civilian and para-public helicopters (Airbus cooperates on 
civilian models, for example the H-175), and India is a defense market. Further, Airbus Helicopter has developed a partnership with South Korea (the KAI Surion, based on a Super Puma platform) and signed contracts to sell its EC-725 Caracal to Thailand and Singapore. Airbus Helicopters is also increasing its exports to Kuwait (30 Caracal), Qatar (which is expected to finalize a contract for the purchase of 22 NH-90), Brazil (Caracal), and Mexico (NH-90). ${ }^{9}$

For its part, Leonardo has developed partnerships to produce its new generation of helicopters with, for example, Turkey (mainly for civilian platforms) and Poland (at the PZL Świdnik plant) and it is also interested in the African market: The firm recently concluded a joint venture in Algeria (Aïn Arnat) to produce light and medium helicopters (transport, Search and Rescue, and scouting).

Cooperation in its various forms makes it possible to maintain industrial skills and knowledge, true, but in the long run there is a risk for strategic skills, although maintained in the short term, to be off-shored. Ultimately, this would weaken both European firms and states in the helicopter sector.

\section{Dual-use helicopters}

Militarized versions of civilian helicopter platforms - dual-use helicopters - may offer several acquisition and support-related advantages. First, sharing the same basic platform, both versions share design and $R \& D$ costs and come off the same assembly line. The resulting economies of scale spread out the fixed costs and therefore reduce unit acquisition costs. Second, economies of scale also increase the efficiency with which spare parts can be supplied, thus lowering support costs. Third, availability of relatively inexpensive spare parts can contribute to decreased helicopter downtime, again saving costs. ${ }^{10}$

Since European helicopter firms are less dependent on military markets (their average military sales dependence is 45 percent) than their American competitors (80 percent), dual use would seem a good option. In addition, the macroeconomic context also matters. For their civilian platforms, the European firms struggle to cope with decreased demand from the oil and gas sectors of the economy. Oil companies represent around half of Airbus Helicopters civilian sales, for example, and no orders were received from this segment of the market in 2015. Leonardo Helicopters, likewise, faces an unfavorable civilian market, although it did have some commercial success with its latest civilian platform, the AW-189. Moreover, European helicopter manufacturers already tend to militarize civilian platforms. The H-145 of Airbus, for instance, initially built for the police, has been militarized and sold to Germany and the Royal Navy of Thailand. In Italy, the HH-139A is a militarized version of the AW-139 civilian platform and is mainly used for search-and-rescue tasks on national territory. And the French future Joint Light Helicopter (the HIL program) will probably be based on a civilian platform designed by Airbus Helicopters.

But can one use militarized versions of civilian helicopters in combat? What in fact are the costs of militarizing a civilian platform and are they less than those of the development of a purely military platform? Military and civilian platforms differ in several ways. First, helicopters for military use need more protection. If passive protection (stealth, armored protection) is too hard to add to a civilian platform, active protection can be arranged for with add-on kits (self-defense systems, sensors, missiles). For example, the AB-212 helicopter was based on civilian standards but is now a combat unit with self-defense systems and in use by Italy's armed forces. Second, weight and load capability play an important role in dual-use helicopter configurations. Third, the use of dual-use helicopters is less effective and efficient for combat mission with ballistic contact than it is for logistical and tactical transport missions.

More broadly speaking, military, security, and civilian users have different needs on three linked dimensions: requirements, price-quality relationship, and time to market. The militarization of a civilian platform is usually a long, complex, and costly process. Armed forces often seek to replace several existing platforms with a single new one. The problem here is that this entails an increase in the number of specifications that are linked to various (and sometimes contradictory) operational and mission needs, and this leads to a more complex and costly platforms, both in acquisition and maintenance. Dual-use helicopters appear better-suited to sovereign missions that are not purely military but more on the security end of the defense-security continuum or to training tasks (e.g., the U.K.'s Defence Helicopter Flying School or France's outsourcing of training fleets). ${ }^{11}$

Of course, one can reverse the question and ask about adapting a military platform to civilian purpose. Many interesting cases can be found in recent history. The Puma and Super Puma helicopters have civilian versions for transport, and many civilian operators use the AW-101 platform for passenger transport. A platform designed to basic military specifications could then remove, case by case, everything that is not in accordance with civilian customer requirements.

\section{The key role of services in helicopter fleet support}

For helicopter manufacturers, the aftermarket or MRO industry (Maintenance, Repair, and Overhaul) has become an important component of the value chain. MRO provides support to users through day-to-day maintenance and required upgrades. Given the lack of investment in new large military programs, a source 
for both future growth and sustained industrial know-how thus lies in extended support of the existing fleets. This should also appeal to governments: As systems have become more costly to buy, keeping ageing fleets in service longer would contain cost and raise readiness. "All-inclusive MRO solutions" with flight hour contracts, in-support service contracts, performance contracts, and so on, are appealing. (And in this the helicopter industry would follow a trend already well-established in other industries: Sell the follow-on service more than the platform.)

For example, Airbus Helicopters won a training contract from the British Ministry of Defence for about GBP500 million on a fleet of 32 helicopters - $29 \mathrm{H}-135$ and $3 \mathrm{H}-145$ - with MRO services included (over 17 years to supply 28,000 hours of training each year). This activity is growing and the company currently provides military helicopter training services for the Royal Air Force at Shawbury, England (38 Squirrel and 14 Griffin helicopters). In 2015, service activities represented almost half of Airbus Helicopters' turnover, a figure that is expected to increase in future. ${ }^{12}$

Already such an evolution toward services is more fully developed in the civilian market (e.g., Ubercopter). Innovations in this sector will probably affect the military sector in years to come. This opens up new market perspectives for European helicopter firms who have produced half of the platforms currently in service (by 2016) and who, according to the International Institute for Strategic Studies, are expected to fulfill some 92 percent of future European helicopter orders. Needless to say, original manufacturers will be better placed than competitors to offer tied-in service packages to their military customers. ${ }^{13}$

Cooperation in MRO will increase in the future and become a crucial issue. Since Europe has not been able to launch and support a common program in the field of military helicopters, cooperation, at least in the short to medium term, is an opportunity to reduce costs and raise platforms readiness. This might be seen as a bottom-up approach for building European defense. Cooperation in maintenance leads to agreements to share stocks of spare parts and of specialized tools and infrastructure, the exchange of specialized workforces, and improved economies of scale by negotiating larger contracts as well as in the training of joint units. Recent European experiences, including the NH-90 and Tiger programs, illustrate the various combinations of possible pooling in the area of support. That said, Tiger helicopter cooperation could be improved with, for example, joint purchases to create a European pooled fleet shared by France, Germany, and Spain. One should also think of concentrating training on a dedicated site instead of using two schools, one in France and the other in Germany. ${ }^{14}$
The European Defense Agency (EDA) is particularly involved in the area of cooperation. In the helicopter sector, it launched a pooling and sharing initiative for skills, knowledge, and experience among European countries with the objective to lower the cost of training through multinational exercises, annual symposia, and training of multinational formations. Between 2009 and 2016, some 206 helicopters, 1,320 aircrew members, and 10,000 infantry deployed to the exercises, held in Belgium, France, Italy, Portugal, and Spain. During this time period, 590 aircrews from 12 countries graduated from the EDA Helicopter Tactics Course and 43 Tactics Instructors from 5 nations graduated from the Helicopter Tactics Instructors Course.

In northern Europe, helicopter maintenance cooperation appears more developed than in the western part of Europe. Northern countries modernize their fleets and have to cope with high infrastructure costs, especially for the newest platforms such as the NH-90s or Black Hawks. To share costs, Denmark, Finland, Norway, and Sweden signed the 2009 Nordic Defence Cooperation (NORDEFCO) agreement to promote military cooperation in the region. In addition, Finland and Sweden recently signed a support agreement for the maintenance of Black Hawk helicopters for 2015-2017 (with possible extension to 2020).

\section{Conclusion}

Helicopters are part of today's strategic defense equipment. In the absence of any large, multi-nation, cooperative program to develop new military helicopters platforms in Europe, a major risk lies in the potential loss of defense industrial and technological knowledge, skills, and military capabilities. This is a crucial issue for the future of European defense, where, for example, no equivalent for the American Joint Multi-Role Program Helicopter is identified.

This article discussed the potential roles that export expansion, increased cooperation, dual use production, or a focus on support and services may play in keeping European military helicopter firms "in play." These options are at best medium-term solutions because sooner or later, governments will need to replace existing platforms, notably for heavy military helicopters. Hence, Europe has to think deeply about how to define the role of the military helicopter of the future. The evolution of technology can create breakthroughs at either extreme of the market: heavy and light platforms. For medium and heavy platforms, high-speed helicopters have become a reality. Now flying at more than $310 \mathrm{~km} / \mathrm{h}$ (the theoretical limit of classical helicopter platforms), for many missions they will compete with fixed-wing aircraft. This creates a new market for helicopter manufacturers, half-way between light aircraft 
and heavy helicopters. In recent years, Bell, with its V-280 Valor, and Leonardo Helicopters have invested massively in the necessary technology. Regarding light platforms, the evolution of technology also changes the market and here the threat comes from the development of Unmanned Aerial Vehicle platforms. UAVs compete increasingly with light helicopters and light aircraft for intelligence, surveillance, and reconnaissance (IRS) or even combat missions.

Europe has launched a preparatory action (EUR90 million for 2017-2019) and planned a budget line of EUR3 billion for upcoming 9th Framework Program for Research (FP9) starting in 2021 (it runs over 7 years' time). In September 2016, the President of the European Commission, Jean-Claude Juncker, announced the creation of a European Defense Fund to support defense investment expenditure. This might be a signal that Europe should invest the necessary R\&D funds to define and study convergence toward common capability needs and to start thinking about the production of a common military helicopter platform. ${ }^{15}$

\section{Notes}

1. Terrestrial/rotary-wing concept: Marrone and Nones (2015).

2. Demand-side need increased: DGRIS-IRIS (2015). 14 countries: IISS (2016, p. 62).

3. 66 percent: Meddah (2016).

4. For historical aspects, see Sheil (1984). Sikorsky: The United States' first military helicopter production contract was actually signed by Georges de Bothezat in 1921. However, it did not lead to any actual industrial-scale production. Market shares: The Russian platforms are in service in Central and East European counties such as Romania, Poland, Bulgaria, Hungary. The share of the Japanese, Indian, and Chinese firms is insignificant.

5. Details about the history of Westland helicopters are taken from http://history.whl.co.uk/.

6. Puma, Gazelle, Lynx: See Bousquet (2016).

7. The aim of Ditchley Park agreements (1975) was to create coherence between helicopter needs among various European armed forces and to reorganize the helicopter industry in Europe. The agreements were signed by a small group of European countries, including France, Germany, and the U.K., and can be considered as the historical starting point of Europewide cooperation in helicopters programs.

8. Aerospatiale: See Sheil (1984).

9. H-175: This is Airbus Helicopter's new designation for the former EC-175, which is the same aircraft.

10. Dual-use: Marrone and Nones (2015, p. 7) write: “'Dual-use helicopters' refer to platforms that have been designed in compliance with certain standards and are structurally built so that they can satisfy civilian, military or security users with only minimal adjustments or additions."

11. Contradictory: For example, heavy armor for the Army versus high speed for the Air Force. On this paragraph, see Belan (2016).

12. Expected to increase: James (2016).

13. Future orders: See IISS (2016).

14. Bottom-up: Droff and Bellais (2016). Dedicated training site: DGRIS-IRIS (2015).

15. European Defense Fund: This fund has not been defined either in its objectives or mechanisms.

\section{References}

Belan, G. 2016. "Hélicoptère Interarmées Léger: Le Casse-Tête!” Air \& Cosmos. No. 2498 (29 April).

Bousquet, G. 2016. "La Cooperation Franco-Britannique," pp. 71-29 in Editions COMAERO, AACHEAr, La Documentation Française. L'histoire des helicoptères en France depuis 1945.

[DGRIS-IRIS] 2015. "Pooling and Sharing Dans Le Domaine Aéroterrestre." Etude Prospective et Stratégique. Paris: Direction générale des relations internationales et de la stratégie (DGRIS) and Institut de Relations Internationales et Stratégiques (IRIS). http://www.iris-france.org/wpcontent/uploads/2015/10/EPS2014-Pooling-andsharing-dans-le-domaine-a $\% \mathrm{C} 3 \% \mathrm{~A} 9$ roterrestre.pdf

Droff, J. and Bellais, R. 2016. "Fleet Management in European Integration: The Case of Military Helicopters Support." Defense \& Security Analysis. Vol. 32, No. 1, pp. 19-35. https://doi.org/10.1080/14751798.2015.1130315

[IISS] Institute for International Strategic Studies. 2016. Military Balance. London: International Institute for Strategic Studies.

James, O. 2016. “En Crise, Les Fabricants D’hélicoptères Préparent La Riposte." L'Usine Nouvelle (February).

Marrone, A. and M. Nones. 2015. "The Role of Dual-Use Helicopters in the Security and Defence Field.” Istituto Affari Internazionali Research Papers.

Meddah, H. 2016. "Les Hélicoptéristes Militaires Entrent En Zone de Turbulences." L'Usine Nouvelle (February).

Sheil, M. 1984. "The Evolution of the U.S. Helicopter Industry." Master's Thesis. Monterey, CA: Naval Postgraduate School.

[SIPRI]. Stockholm International Peace Research Institute. 2016. Arms Industry Database, 2002-2015. 